\title{
IPTEK PENGOLAHAN LIMBAH PETERNAKAN MENJADI PUPUK ORGANIK KUALITAS PABRIKAN DI KELOMPOK TERNAK LIMUSIN JAGIR, DESA KEMUNING LOR, KABUPATEN JEMBER
}

\author{
SCIENCE AND TECHNOLOGY FOR PROCESSING ANIMAL WASTE INTO \\ ORGANIC FERTILIZER WITH QUALITY OF FACTORIES IN THE LIMUSIN \\ JAGIR LIVESTOCK GROUP, KEMUNING LOR VILLAGE, JEMBER DISTRICT
}

\author{
Suci Wulandari ${ }^{\# 1}$, Hariadi Subagja ${ }^{* 2}$, Dyah Laksito Rukmi ${ }^{\# 3}$ \\ \#1,2,3 Jurusan Peternakan, Politeknik Negeri Jember \\ Jl. Mastrip PO BOX 164, Jember \\ ${ }^{1}$ suciepolije.ac.id \\ ${ }^{2}$ hariadi subagjaepolije.ac.id \\ ${ }^{3}$ dyahlaksito.spt.msiegmail.com//
}

\begin{abstract}
Abstrak
Permasalahan utama di Kelompok ternak 'Limusin Jagir" adalah membutuhkan pendapatan tambahan secara kontinyu dari usaha peternakan sapi dan kambing. Pembuatan pupuk organik yang bermutu merupakan alternatif solusi yang baik. Hal ini dikarenakan:1)Bahan baku pembuatan pupuk organik berupa kotoran ternak, ketersediaannya selalu ada; 2)Daya terima konsumen dan pemasaran pupuk organik cukup baik. Tujuan kegiatan pengabdian ini adalah: 1)Memberikan bekal pengetahuan dan ketrampilan mengenai penggunaan starter mikrobia akan dihasilkan pupuk organik yang lebih cepat (hanya 21 hari sampai 28 hari dari umumnya lebih dari 5 bulan) dan berkualitas, yaitu bentuknya remah dan sudah dingin siap pakai untuk digunakan sebagai sumber makro mineral dan mikro mineral yang lengkap bagi tanaman. Jenis mikrobia yang dapat mengurai bahan organik antara lain Bacillus sp., Aeromonas sp., dan Aspergilus nigger. Mikrobia ini dapat dibuat sendiri dalam bentuk mikrobia lokal atau MOL, maupun yang tersedia di toko yaitu EM4; 2)Memberikan wawasan dan ketrampilan cara pengemasan yang kuat dan menarik, dapat meningkatkan nilai jual produk dan memberikan produk khas Desa Kemuning. Metode pelaksanaan seliputi: a)persiapan kegiatan, kemudian dilakukan b)penyuluhan, c)pelatihan dan bantuan peralatan pendukung, serta d)evaluasi kegiatan. Hasil kegiatan dapat disimpulkan bahwa: 1)Kegiatan pengabdian mendapat respon positip dari kelompok peternak; 2)Pemberian bantuan berupa mesin jahit karung, peralatan pembuatan pupuk seperti sekop, terpal, dan sak kemasan dengan ukuran $5 \mathrm{~kg}$ dan $15 \mathrm{~kg}$, bahan untuk pembuat pupuk organik, seperti starter, tetes, sekam dan kapur. Pemberian alat bahan dimaksudkan sebagai contoh macam-macan alat dan bahan yang digunakan dalam pembuatan pupuk organik; dan 3)Respon para peternak sangat antusias dengan aktif mengikuti kegiatan saat pengabdian, dan langsung mengaplikasikan pada tanaman sayurnya.
\end{abstract}

Kata Kunci-Desain kemasan, Kemuning Lor, Limbah peternakan, Pupuk organik,.

\section{Abstract}

The main problem in the "Jagir Limousine" livestock group was that it required continuous additional income from the cattle and goat farming business. Making a quality organic fertilizers was a good alternative solution. This was because: 1) The raw material for making organic fertilizer was livestock manure, its availability was always available there; 2) The consumer and marketing of organic fertilizers was quite good. The objectives of this service were: 1) Providing knowledge and skills regarding the use of microbial starters to produce organic fertilizers which were faster (only 21 days to 28 days than generally more than 5 months) and had an high quality, namely in the form of crumbs and ready to use for a complete source of macro minerals and micro minerals for plants. The types of microbes could break down organic matter include Bacillus sp., Aeromonas sp., and Aspergilus nigger. These microbes could be made the local microbes, or those available in farm shops, namely EM4; 2) Provide an extensive knowledge and skills in good quality and attractive packaging methods, could increase product selling value and provide specific products of Kemuning Village. The implementation methods were a) preparation of activities, then carried out by b)assistance, c) training and giving supporting equipments, and d) evaluation of activities. The results of the activity could be concluded that: 1) Community service activities received a positive response from the farmer group; 2) Provision of a sack sewing machine, fertilizer manufacturing equipment such as shovels, tarpaulins, and packaged sacks with sizes of $5 \mathrm{~kg}$ and $15 \mathrm{~kg}$, materials for making organic fertilizers, such as starters, drops, husks and lime. The provision of material tools were expected to be an example of the kinds of tools and materials used in the manufacture of organic fertilizers; and 3) The responses of the farmers were very enthusiastic by actively participating in the activities during the program, and immediately applying them to their vegetable crops.

Keywords — Packaging design, Kemuning Lor, Animal husbandry waste, Organic fertilizers. 


\section{PENDAHULUAN}

Paragraf selanjutnya mengikuti format seperti dalam dokumen ini. Antar alinea dalam satu bab tidak ada spasi. Antar bab dapat diberi satu spasi seperti contoh.

Peternak sapi dan kambing di Desa Kemuning Lor tergabung dalam kelompok ternak yang bernama Limusin Jagir. Kepemilikan ternak anggota kelompok cukup sedikit, yaitu antara 1-2 ekor sapi atau kambing sekitar 7-8 ekor untuk setiap anggota kelompok. Kondisi ini menunjukkan bahwa usaha peternakan di Desa Kemuning Lor belum bisa dijadikan sebagai usaha utama untuk memenuhi kebutuhan keluarga setiap harinya. Untuk itu dalam pengabdian Polije Sumber dana PNBP ini, tim pengabdian berupaya memaksimalkan pendapatan peternak dengan memanfaatkan limbah kotoran ternak untuk diolah menjadi pupuk organik,

Pupuk organik adalah pupuk yang sebagian besar atau seluruhnya terdiri dari bahan organik yang berasal dari tanaman dan atau hewan yang telah melalui proses rekayasa, dapat berbentuk padat atau cair yang digunakan untuk mensuplai bahan organik, memperbaiki sifat fisik, kimia dan biologi tanah [1](Permentan, 2006). Jenis mikrobia yang telah diidentifikasi dapat mengurai bahan organik antara lain Bacillus sp., Aeromonas sp., dan Aspergilus nigger [2]. Pupuk organik mempunyai fungsi antara lain adalah: 1) memperbaiki struktur tanah, karena bahan organik dapat mengikat partikel tanah menjadi agregat yang mantap, 2) memperbaiki distribusi ukuran pori tanah sehingga daya pegang air tanah meningkat dan pergerakan udara (aerasi) di dalam tanah menjadi lebih baik [3].

Tujuan kegiatan pengabdian ini adalah: 1)Memberikan bekal pengetahuan dan ketrampilan mengenai penggunaan starter mikrobia akan dihasilkan pupuk organik yang lebih cepat (hanya 21 hari sampai 28 hari dari umumnya lebih dari 5 bulan) dan berkualitas, yaitu bentuknya remah dan sudah dingin siap pakai untuk digunakan sebagai sumber makro mineral dan mikro mineral yang lengkap bagi tanaman. Mikrobia ini dapat dibuat sendiri dalam bentuk mikrobia lokal atau MOL, maupun yang tersedia di toko yaitu EM4; 2)Memberikan wawasan dan ketrampilan cara pengemasan yang kuat dan menarik, dapat meningkatkan nilai jual produk dan memberikan ciri khas produk Desa Kemuning.

Manfaat dari transfer teknologi dalam pengolahan kotoran menjadi pupuk organik oleh tim Jurusan peternakan mempunyai kelebihan dari yang ada pada umumnya, antara lain: 1)waktu yang diperlukan lebih cepat, sehingga mempercepat dalam memperoleh pendapatan, yaitu cukup 21 sampai 28 hari dari umumnya yang membutuhkan waktu berbulan bulan (lebih 5 bulan); 2)Peternak memndapatkan wawasan dan ketrampilan pupuk organik yang menarik dan kuat, sehingga akan menunjukkan ciri khas desa.

\section{TARGET DAN LUARAN}

Target dan luaran yang diharapkan dalam kegiatan pengabdian ini adalah: 1)Mitra mendapat pengetahuan dan ketrampilan dalam pengolahan kotoran ternak bermutu dalam waktu yang cepat 21 sampai 28 hari dari umumnya yang membutuhkan waktu lebih dua bulan dan 2)Mitra dapat memproduksi dan mengemas produk pupuk organik secara menarik dan kuat, serta menjadi produk unggulan Desa Kemuning Lor.

\section{METODE PELAKSANAAN}

Berdasar hasil diskusi dengan kelompok ternak Limusi Jagir yang beralamat di Desa Kemuning Lor, Kecamatan Arjasa, Kabupaten Jember, maka Tim Pengabdian melakukan kegiatan program pengabdian pada masyarakat dengan sumber dana PNBP Politeknik Negeri Jember (Polije) untuk mengatasi masalah yang ada di desa Kemuning Lor. Kegiatan tersebut meliputi: penyuluhan dan pelatihan, pemberian bantuan peralatan pendukung, serta evaluasi kegiatan.

Tim kegiatan terdiri dari ketua pengabdian yang bertanggung jawab pada seluruh kegiatan, dan dua orang anggota yang masing-masing bertanggung jawab dalam kegiatan pemberian pengetahuan dan ketrampilan pembuatan pupuk, dan anggota yang lain bertanggung jawab dalam kegiatan penyuluhan dan praktek dalam pengabdian. Kegiatan pengabdian ini mengikut sertakan dua orang mahasiswa yang membantu dalam dalah kegiatan penyuluhan dan praktek dalam pengabdian.

\section{HASIL DAN PEMBAHASAN}

Berdasarkan hasil diskusi dengan kelompok ternak Limusi Jagir yang beralamat di Desa Kemuning Lor, Kecamatan Arjasa, Kabupaten Jember, maka Tim Pengabdian melakukan kegiatan program pengabdian pada masyarakat dengan sumber dana PNBP Politeknik Negeri Jember (Polije) untuk mengatasi masalah yang ada di desa Kemuning Lor. Kegiatan tersebut meliputi: penyuluhan dan pelatihan, pemberian bantuan peralatan pendukung, serta evaluasi kegiatan.

Tim kegiatan terdiri dari ketua pengabdian yang bertanggung jawab pada seluruh kegiatan, dan dua orang anggota yang masing-masing bertanggung jawab dalam kegiatan pemberian pengetahuan dan ketrampilan pembuatan pupuk, dan anggota yang lain bertanggung jawab dalam kegiatan penyuluhan dan praktek dalam pengabdian. Kegiatan pengabdian ini mengikut sertakan dua orang mahasiswa yang membantu dalam dalah kegiatan penyuluhan dan praktek dalam pengabdian. 
Kegiatan yang telah dilaksanakan selama berlangsungnya pengabdian, meliputi: persiapan, penyuluhan, serta pelatihan dan pemberian bantuan peralatan pendukung. Evaluasi dan diskusi masih berlangsung hingga saat ini.

\section{a. Persiapan}

Sebelum dilakukan kegiatan, tim dosen dan mahasiswa Polije melakukan sosialisasi pada anggota mitra sekaligus mendiskusikan tentang kegiatan yang akan berjalan, serta penyesuaian waktu dan lokasi, agar pelaksanaan pengabdian dapat berjalan lancar. Persiapan dilakukan dengan cara datang ke lokasi langsung di desa Kemuning maupun dengan alat telekomunikasi handphone.

\section{b. Penyuluhan dan Pelatihan}

Model kegiatan dengan cara memodifikasi penyuluhan, tidak hanya teori atau presentasi saja tetapi banyak dilakukan praktek dan demonstrasi. Metode ini lebih diterima masyarakat awam, dikarenakan anggota peternak yang diberi pembekalan materi tentang pupuk organik sambil melakukan praktek secara langsung, sehingga langsung dapat dimengerti. Adapun materi yang diberikan adalah:

- Pertanian Zero waste

- Macam-macam pupuk organik

- Produk dan Daya Tarik Konsumen

Pelatihan dilaksanakan di rumah ketua kelompok ternak Limusin Jagir, yaitu Bapak Suryanto yang beralamat di Desa Kemuning Lor, Kec. Arjasa, Kabupaten Jember (Gambar 1). Pelatihan dilakukan sebanyak dua kali. Pertama adalah penyuluhan dan praktek pembuatan pupuk organik. Pelatihan kedua adalah pemanenan pupuk, dan praktik pengemasan pupuk secara menarik. Diantara waktu kegiatan, peternak diberi tugas mandiri untuk mengaduk pupuk dan mendokumentasikan hasil yang diperoleh setiap minggunya.

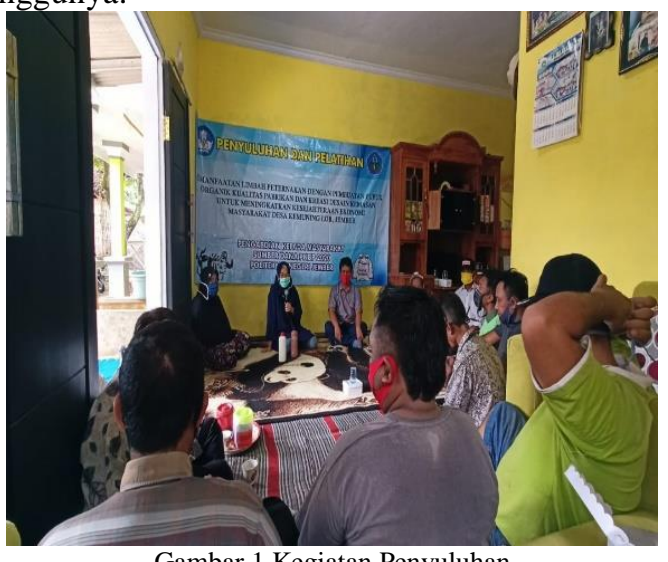

Gambar 1 Kegiatan Penyuluhan

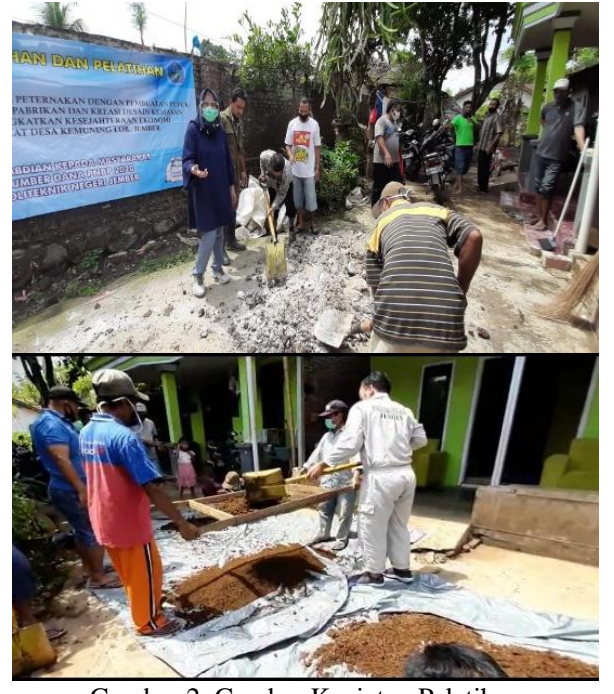

Gambar 2. Gambar Kegiatan Pelatihan

Kegiatan dilakukan dengan menggunakan peralatan dan bahan dari pihak Politeknik Negeri Jember. Diawali dengan mencampur bahan-bahan yang diperlukan berupa kotoran ternak / feses sebanyak $200 \mathrm{~kg}$, sekam $10 \mathrm{~kg}$, kapur $5 \mathrm{~kg}$. Bahan tersebut diaduk merata, kemudian dicampur dengan mikrobia yang telah diaktifkan dengan air tetes $2 \%$ selama sekitar satu jam, dan diaduk secara merata. Mikrobia yang digunakan ada dua macam, yaitu produk pabrikan berupa EM4 dan buatan tim pengabdian. Setelah merata, ditutup dengan terpal. Setiap seminggu sekali anggota peternak diberi tugas untuk membuka terpal dan melakukan pengadukan. Setelah empat minggu pupuk organik yang telah jadi dilakukan pengayakan dan pengemasan. Selama kegiatan pelatihan di bimbing dan di damping langsung oleh tim pengabdian Polije yang terdiri dari 3 orang dosen, 1 teknisi, dan 2 orang adik mahasiswa. Sesi diskusi dan tanya jawab dilakukan saat kegiatan pelatihan (Gambar 2).

\section{c. Pemberian bantuan peralatan pendukung}

Pemberian bantuan berupa mesin jahit karung, peralatan pembuatan pupuk seperti sekop, terpal, dan sak kemasan yang telah di sablon dengan beberapa ukuran bahan untuk pembuat pupuk organik, seperti starter, tetes, sekam dan kapur. Pemberian bantuan bahan dan alat ini dimaksudkan untuk menstimulir kelompok ternak di Desa Kemuning dalam mengembangkan usahanya, agar dapat berhasil dan dapat meningkatkan pendapatan usahanya. Bemberian bantuan alat diberikan oleh P3M yang secara simbolis diwakilkan oleh anggota tim pengabdian dan diterimakan oleh ketua kelompok ternak Limusin Jagir (Bpk Suryanto) (Gambar 3).

\section{d. Evaluasi}

Evaluasi dimaksudkan untuk mengetahui kekurangan dan kelebihan terhadap kegiatan yang 
telah dilakukan dalam rangka untuk menetapkan rekomendasi terhadap kelangsungan dan pengembangan kegiatan berikutnya.

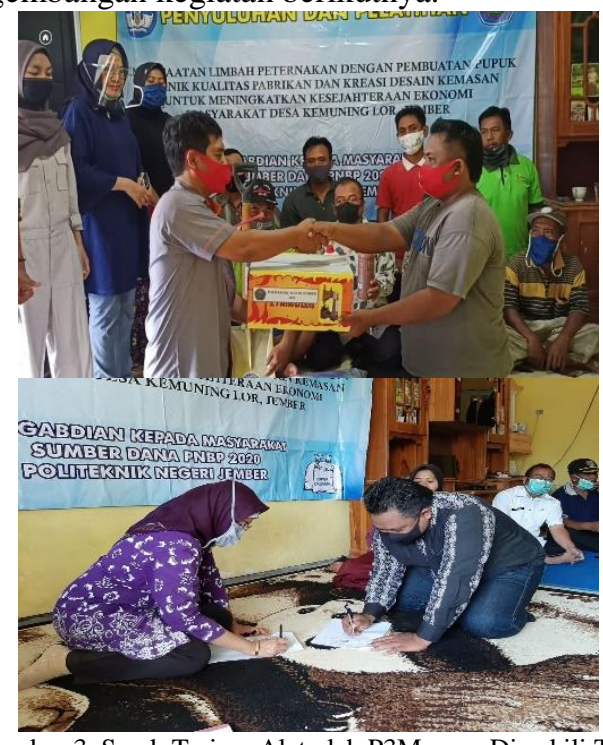

Gambar 3. Serah Terima Alat oleh P3M yang Diwakili Tim Pengabdian

Kegiatan pengabdian ini telah dilakukan dengan lancar dan sukses, hal ini ditunjukkan dengan nilai kemanfaatan bagi anggota kelompok ternak Limusin Jagir yang sangat membutuhkan pengolahan kotoran yang selama ini mencemari lingkungan dan solusi mengatasi permasalahan harga pupuk yang mahal. Anggota kelompok juga sangat antusias dalam mengikuti setiap kegiatan hingga kegiatan selesai. Para perangkat desa juga memberikan support dengan hadir nya Bapak Kepala Desa dan Bapak Sekertaris desa pada kegiatan pengabdian ini.

\section{DAFTAR PUSTAKA}

[1] Peraturan Menter Pertanian, Pupuk organik dan pembenah tanah. [Online]. Tersedia:

http://perundangan.pertanian.go.id/admin/p_mentan/Perme ntan-02-06.pdf 2006

[2] Rohman, W. F., Satriya B. P., dan Adrian K. P., Nasionalisasi pengolahan sampah (Zero Waste Concept) dalam rangka menyukseskan Indonesia mandiri pangan sekaligus membudayakan barter bahan pangan agar terjalin hubungan rukun antar tetangga, Kumpulan Inovasi Anak Negeri Mahasiswa UGM, [Online], Tersedia: http://kreativitas.ugm.ac.id/site/wpcontent/uploads/2015/11/Zero.pdf, Yogyakarta, 2016

[3] Hayati, E., T. Mahmud, dan R. Fazil., Pengaruh jenis pupuk organik dan varietas terhadap pertumbuhan dan hasil tanaman. Banda Aceh:J. Floratek, vol. 7, pp173-181, 2012. 